\title{
Leaders
}

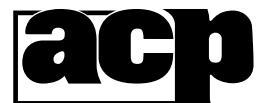

Best Practice No 163

\section{Wilson's disease: acute and presymptomatic laboratory diagnosis and monitoring}

\author{
D Gaffney, G S Fell, D St J O’Reilly
}

\begin{abstract}
Wilson's disease, the most common inherited disorder of copper metabolism, is a recessive genetic condition. The clinical presentation of Wilson's disease is very variable. It is characterised by low serum copper and caeruloplasmin concentrations coupled with the pathological accumulation of copper in the tissues. However, there are diagnostic difficulties and these are discussed. The current value of DNA diagnosis, both in gene tracking in families or as applied to de novo cases, is examined. Wilson's disease can be treated successfully but treatment must be life long. Patients are best treated by specialist centres with experience and expertise in the condition.

(F Clin Pathol 2000;53:807-812)
\end{abstract}

Keywords: Wilson's disease; copper; diagnosis

Wilson's disease, or hepatolenticular degeneration, is the most widely investigated inborn disorder of copper metabolism. ${ }^{1}$ Wilson's disease is characterised by an inadequate excretion of absorbed dietary copper via bile resulting in the accumulation of toxic amounts of copper in the liver and other organs. It is inherited as a rare autosomal recessive condition with an incidence of one in 30000 live births in most populations, and with a calculated carrier frequency in the general population of one in 90. ${ }^{2}$ The disease can present without warning at a variety of ages and in different forms. This article has been written with two different patient situations in mind. First, it is a reminder of the importance of considering Wilson's disease as a diagnosis in unexplained presentations of liver or neurological disease, especially in adolescents or young adults; second, it describes the genetic investigation of siblings of an individual with the condition (presymptomatic diagnosis).

\section{Copper metabolism}

Copper is an essential micronutrient but ionic copper is toxic. The toxic effects are thought to be mediated by the generation of reactive oxygen free radical species. Total dietary intake of copper ranges from $<1-5 \mathrm{mg} /$ day, and some $20-60 \%$ of this is absorbed from the small intestine and transported, bound to albumin, via the portal blood to the liver. The liver is the main regulator of copper metabolism. In the hepatocyte, copper is distributed among the various copper metalloenzymes and also incorporated into the plasma protein caeruloplasmin, where it re-enters the circulation. Caeruloplasmin bound copper accounts for over $90 \%$ of plasma copper. In the bile, specific isoforms of caeruloplasmin have been identified that appear to be involved in copper excretion. ${ }^{3}$ Wilson's disease is caused by a failure of this excretory pathway, resulting in toxic accumulation of the metal in the liver and eventually in other organs. The role of copper in the environment and in human medicine has recently been reviewed. ${ }^{4}$

\section{Presentation of Wilson's disease}

The presentation of Wilson's disease is very variable. It presents as chronic liver disease in about $42 \%$ of cases, and as neurological disease in another $34 \%$ of cases. ${ }^{5}$ Wilson's disease is not a cause of mental retardation. Other presentations include psychiatric disorders, haemolytic anaemia, and renal tubular lesions. Presentation as acute liver failure is rare, ${ }^{67}$ but may require urgent diagnosis and transplantation. The copper initially accumulates in the liver and as a result younger patients tend to exhibit hepatic presentations. ${ }^{8}$ The accumulation of copper in the cornea of the eye leads to the characteristic Kayser-Fleischer (KF) rings. 
Corneal copper deposition is helpful in diagnosis, but it does not affect the function of the eye; however, in other tissues damaging effects of copper are seen. For example, accumulation in the skin leads to hyperelasticity; in the joints it leads to early onset osteoarthritis, particularly of the spine; and in the kidney it leads to renal tubular disorders. $\mathrm{KF}$ rings are indicative of pathological copper accumulation load in the central nervous system and are a late manifestation of the condition. In many cases, Wilson's disease is difficult to diagnose, especially if $\mathrm{KF}$ rings are not present. Even centres with expertise regard diagnosis as a challenge in some cases. $^{9}$

\section{Principles of treatment}

Patients are best cared for at specialist centres. Chelation is the mainstay of treatment, the principles of which are as follows ${ }^{10}$ :

(1) Reducing copper absorption. Oral zinc induces intestinal mucosal metallothionein, which avidly binds copper. The copper is then excreted in the faeces when the mucosal cells are shed in the normal fashion. Oral zinc before meals is a very safe but slow acting form of treatment. (Tetrathiomolybdate forms a complex with dietary copper in the gut and thus prevents intestinal absorption. This treatment is still at the experimental stage and is not yet approved for clinical use.)

(2) Chelation treatment. Penicillamine ${ }^{11}$ and trientine complex absorbed copper, which is subsequently excreted in the urine. These treatments can rapidly reduce the copper burden. However some patients can develop hypersensitivity to penicillamine with arthralgia and rashes, although these may be transient. Clearly, it is inappropriate to use zinc and chelation simultaneously.

(3) Patients who develop fulminant hepatic failure may require transplantation.

When treatment should begin in asymptomatic cases detected when families are screened is controversial.

With appropriate management, female patients identified as having Wilson's disease as children have had successful pregnancies. ${ }^{12}$

\section{Monitoring treatment}

Chelation treatment increases urinary copper excretion and this can be used to monitor compliance and the extent of decoppering.

Stable copper isotope uptake can be measured to monitor the effective dosage of zinc (usually for research purposes).

With decoppering, sequential magnetic resonance imaging scanning appears to show resolution of the neurological abnormalities. ${ }^{13}{ }^{14}$

An essential aspect of treatment is to educate the patient that treatment must continue for life. Even individuals who, after two or three decades of treatment, cease to take their penicillamine can have serious liver damage resulting in death in less than two years. ${ }^{15}$ Therefore, life long compliance is essential and is best ensured by six monthly visits to a specialist centre with clinical examination and monitoring for hepatic, neurological, and other complications.

Molecular defect causing Wilson's disease The mutations responsible for the disease are within a gene that normally encodes a copper transporting adenosine triphosphatase (ATPase). The mutations cause a decrease or absence of the gene product or production of a protein with impaired function. This results in reduced copper transport within the hepatocyte and failed insertion of copper into caeruloplasmin. As a consequence, in most patients with Wilson's disease serum caeruloplasmin and total serum copper concentrations are low, but there is an increased proportion of low molecular weight copper species in serum. This eventually allows deposition of excess copper in the liver, brain, eye, and other tissues, leading to the variable clinical symptoms. Absence of the protein in the kidney impairs tubular reabsorption of filtered copper with resultant increased urine copper excretion.

\section{Genetics}

Wilson's disease is an autosomal recessive condition with the defect on chromosome $13 .^{16}$ The gene was cloned and identified in $1993,{ }^{17}{ }^{18}$ and shown to encode a copper transporting P type ATPase with homology to the Menkes disease gene. The gene is named ATP7B and its product is expressed primarily in liver but also in kidney, stomach, spleen, and other tissues. ${ }^{19}$ In the few cases where liver transplantation has been performed, it has alleviated many of the symptoms. Thus, the importance of the expression of small amounts of the gene product in tissues other than liver in humans is not known.

As DNA from different individuals with Wilson's disease was sequenced, owing to the many causative mutations of the disease, it quickly became evident that simple DNA diagnosis was not going to be possible. Eighty nine disease specific mutation ${ }^{20}$ in the ATP7B gene are already known (for the latest information see http://www.medgen.med.ualberta.ca/ database.html) and most patients (sometimes called homozygotes) are in fact compound heterozygotes. Some mutations are sufficiently common in certain populations to consider screening for them (see below), ${ }^{21}$ but there is also still a major role for linkage analysis in the preclinical and prenatal diagnosis of the condition. ${ }^{22}$ Different mutations provide a partial explanation of the spectrum of disease. ${ }^{23}$ Cloning and identification of the gene has enabled further confidence in identification of several flanking microsatellite markers, which are used for gene tracking and diagnosis within families. $^{24}$

\section{Investigation strategy}

See fig $1 .{ }^{925}$

LOCAL INVESTIGATIONS

Caeruloplasmin and copper measurements

The measurement of serum caeruloplasmin and copper concentrations should be available 


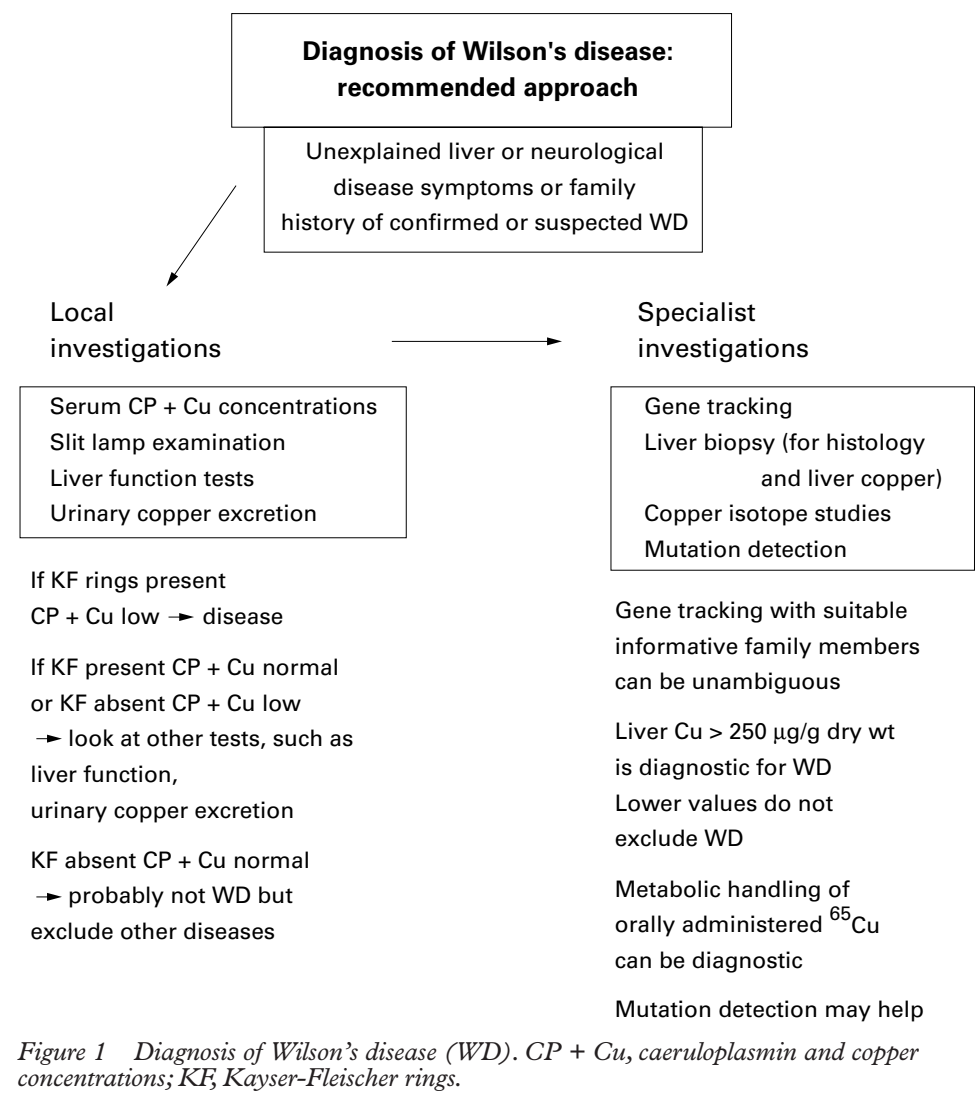

locally via most hospital laboratories. The reference range for serum caeruloplasmin is between 200 and $600 \mathrm{mg} /$ litre (there may be some local variation depending on the method used). Caeruloplasmin should be measured immunochemically by turbidimetry or nephelometery, although radial diffusion is also acceptable. The method should be capable of accurately measuring caeruloplasmin at a concentration as low as $100 \mathrm{mg} /$ litre. The reference range for serum copper is $10-22 \mu \mathrm{mol} /$ litre. It should be measured using a flame atomic absorption spectrometer or an inductively coupled plasma optical emission spectrometer.

For both copper and caeruloplasmin measurements, a $5 \mathrm{ml}$ plain tube of blood is appropriate; for paediatric samples enquire at the local laboratory for minimum volumes.

The combination of serum caeruloplasmin below $200 \mathrm{mg} /$ litre with $\mathrm{KF}$ rings is diagnostic for the disease. ${ }^{4}$ Other medical conditions can cause low serum copper and caeruloplasminfor example, nephrotic syndrome-but these conditions can be excluded in most cases on clinical grounds. In less clear cut cases, serum copper below $8.0 \mu \mathrm{mol} /$ litre and/or impaired liver function can indicate Wilson's disease. Some care in interpretation of these results must be taken because carriers of the condition have serum copper and caeruloplasmin concentrations at the bottom end of, or just below, the reference range. To complicate the situation further, not all patients with Wilson's disease have low serum caeruloplasmin. ${ }^{9}$

Further information can be gleaned by the calculation of free (non-caeruloplasmin bound) copper. Non-caeruloplasmin bound copper (Non-Cp-Cu) can be calculated as follows :

Non-Cp-Cu $(\mu \mathrm{mol} / \mathrm{l})=$ total serum $\mathrm{Cu}(\mu \mathrm{mol} / \mathrm{l})$ - $0.047 \times$ serum Cp (mg/litre)

The factor multiplying the serum caeruloplasmin concentrations is derived from the molecular weight of caeruloplasmin (24) and the number of copper atoms (six) bound to it.

Normally, non-caeruloplasmin bound copper is less than $10 \%$ of the total copper but it can be increased to $30-50 \%$ in Wilson's disease. Interpretation of the values should bear in mind the imprecision of measurement of caeruloplasmin if the serum concentration is below $60 \mathrm{mg} /$ litre.

Note that in acute liver failure concentrations can be increased to $30-50 \mu \mathrm{mol} /$ litre total serum copper, with greatly increased calculated non-caeruloplasmin copper (70-80\%).

\section{Ophthalmic slit lamp eye examination}

As already mentioned, this can reveal characteristic copper deposits in the cornea (KF rings). Their presence, especially in combination with other signs and symptoms, is diagnostic of Wilson's disease but their absence does not exclude the disease. Interestingly, $\mathrm{KF}$ rings are almost never seen in children and are more typically associated with neurological presentations. KF rings may be visible to the naked eye as brown rings in the periphery of the cornea against the blue/green background of the iris. This may appear grey in patients in whom the iris is brown. ${ }^{1}$ They may also be present in the very late stages of primary biliary cirrhosis, but in these cases the clinical setting will exclude Wilson's disease.

\section{Liver function tests}

The abnormalities of liver function associated with Wilson's disease are very variable. In some cases, all parameters will be within their respective reference ranges. Some cases may have a minor increase in aspartate amino transferase and an increased lactate dehydrogenase, as a result of either low grade haemolysis (when serum haptoglobin will also be low) or hepatic cellular damage. Others may have progressed to full blown cirrhosis, with increased bilirubin and alkaline phosphatase, and a low hepatic protein synthetic capacity resulting in a low serum albumin and a prolonged prothrombin time.

\section{Urinary copper}

In healthy individuals, $<1.0 \mu$ mole of copper is excreted in the urine daily. In Wilson's disease, the urinary copper output is $>1.5 \mu$ moles $/ 24$ hours. Contamination of the collection vessel can be a major problem when measuring urinary copper, and can give rise to a false positive result. Therefore, it is essential that the urine container is copper free, which can be achieved by extensive washing with copper free water. The laboratory must also be capable of accurately and precisely measuring copper at low concentration. 
Penicillamine challenge test

In all subjects (healthy controls, patients with all forms of liver disease, heterozygote carriers of Wilson's disease, and patients with Wilson's disease) penicillamine increases urinary copper excretion. The increase in copper excretion is very variable. In one older study, urinary copper increased 4-16-fold in patients with Wilson's disease after $1 \mathrm{~g}$ of penicillamine. ${ }^{26}$ In heterozygote carriers the increase varied from eight to 55-fold, with greater increases seen in healthy controls. A urinary copper excretion of $>25 \mu$ moles $/ 24$ hours after a $1 \mathrm{~g}$ dose of penicillamine is considered to be compatible with a diagnosis of Wilson's disease. ${ }^{27}$ We no longer recommend this test because of difficulties in interpretation; however, some laboratories have found it useful. ${ }^{28}$

\section{SPECIALIST INVESTIGATIONS}

Liver biopsy

Liver copper content $>250 \mu \mathrm{g} / \mathrm{g}$ dry weight is diagnostic for Wilson's disease. The reference range for liver copper is $12-84 \mu \mathrm{g} / \mathrm{g}$ dry weight. Great care must be taken to obtain a representative liver sample because small samples are particularly prone to inaccuracies when the copper content is extrapolated to the whole liver. $^{29}$ Sometimes liver biopsy cannot be undertaken because of bleeding difficulties or for other reasons.

Copper accumulates in the liver in cirrhotic obstructive liver disorders, such as primary biliary cirrhosis. In primary biliary cirrhosis the liver copper concentration can be as high as in Wilson's disease. The clinical presentation will usually enable a distinction to be made between Wilson's and other diseases causing chronic obstructive liver disease and cirrhosis.

Histomorphology studies of the liver are unhelpful because a wide spectrum of histological findings has been reported, with no characteristic feature of Wilson's disease in its early stages. Stainable copper is only detected when liver copper is grossly abnormal.

\section{Copper isotope incorporation studies}

In ambiguous cases, copper isotope incorporation into serum components after oral dosage can be measured. ${ }^{30}$ A normal response excludes Wilson's disease, whereas failure to produce serum enrichment by three to four days is indicative of Wilson's disease or heterozygosity. Historically, radioactive copper ${ }^{64} \mathrm{Cu}$ (half life, 13 hours) or ${ }^{67} \mathrm{Cu}$ (half life, 62 hours) have been used for metabolic studies. However, these are available only for a very short period of time every few years. In most countries, they have been replaced by the stable copper $\left({ }^{65} \mathrm{Cu}\right)$ isotope, which is safe, suitable for use in children, and continuously available. Figure $2 \mathrm{~A}$ illustrates normal copper kinetics. Figure 2B illustrates the kinetics of a patient with Wilson's disease (note the difference of scale in figs $2 \mathrm{~A}$ and B) and the efficacy of zinc in blocking copper absorption in a patient. For adult studies, $3 \mathrm{mg}$ of ${ }^{65} \mathrm{Cu}$ (this may be in the form of copper nitrate) is given orally. This can be done locally on outpatients. Blood samples are collected for the next three days. The samples are stable at
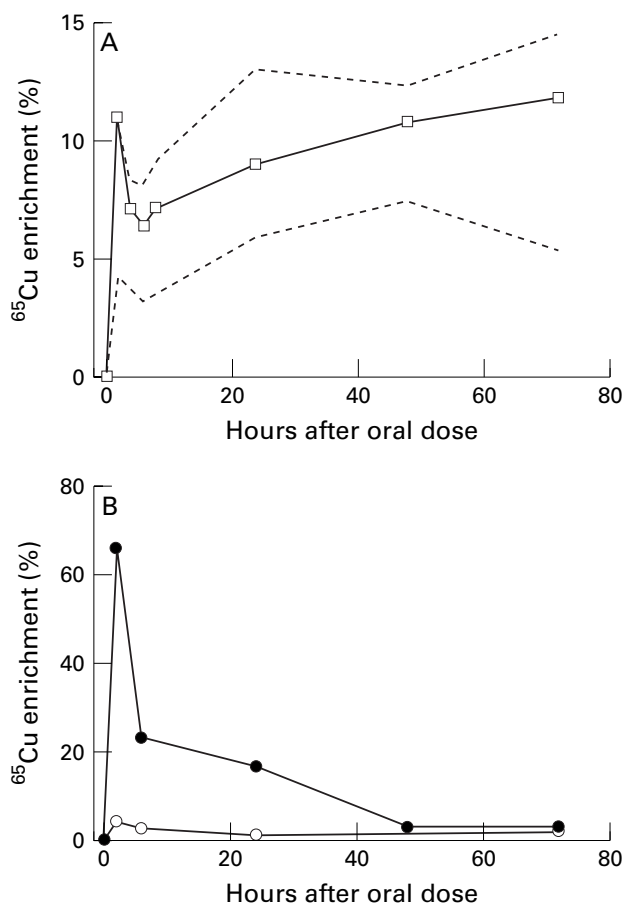

Figure 2 (A) Mean ${ }^{65} \mathrm{Cu}$ enrichment time curve for serum after an oral dose of ${ }^{65} \mathrm{Cu}$ in healthy control subjects. The broken lines give the upper and lower bounds. (B) ${ }^{65} \mathrm{Cu}$ enrichment time curves for patients with Wilson's disease treated with penicillamine (filled circles) or with zinc (open circles). Note the difference in scale from panel $(A){ }^{30}$

ambient temperature, and the serum may be sent by post to the laboratory.

\section{Genetic investigation: gene tracking}

Genetic diagnosis is most valuable within a family where there is already DNA available from an established case. Although this approach has been possible using linked genes, ${ }^{31}$ its potential for diagnosis rather than research was realised after the cloning of the gene and the description of multi-allele microsatellite markers. ${ }^{32}{ }^{33}$ Gene tracking can be successfully applied, and is particularly useful in families where a newly diagnosed child has siblings who could be presymptomatic or unaffected.

\section{Genetic investigation: mutation detection}

At the time of writing there is no practical way to diagnose all patients with Wilson's disease by direct genetic analysis of the gene for causative mutations. This is partly because of the number of different mutations (almost 100 mutations have already been reported) and also because of the possibility that lack of the Wilson's disease protein could be the result of mutations in non-coding regions of the gene instead of within the coding sequences. As a research project it would conceivably be possible to amplify all the individual exons from both alleles (using the polymerase chain reaction) in an individual and to sequence these, and in many patients two mutations would be found. The amount of work makes this approach completely unrealistic, especially because failure to detect mutations would not exclude Wilson's disease. However, there are three relatively common European mutations 
causing Wilson's disease and a service to detect these is available (see below).

Genetic diagnosis could be applied to de novo cases but is not recommended because the chances of an unambiguous result are low. If genetic testing detects the presence of two mutant alleles then Wilson's disease is confirmed even without a family history. For any patient with Wilson's disease the chances of this are approximately $36 \%$. Any other result (none or one mutant allele) cannot be taken as evidence that the person does not have Wilson's disease because the disease could be caused by a more rare mutation.

\section{SAMPLE REQUIREMENTS}

Genetics

Blood samples in EDTA tubes $(\leqslant 10 \mathrm{ml})$ can be sent by first class post to an appropriate DNA laboratory. Contact the laboratory first to ensure the correct samples to send, and whether sufficient family members are available to make it worthwhile to apply gene tracking.

Many genetics laboratories will be able to apply the gene tracking procedures to detect the microsatellite markers on either side of the Wilson's disease gene. The North Trent Molecular Genetics Service (contact Dr Diana Curtis, Centre for Human Genetics, 117 Manchester Road, Sheffield S10 5DN, UK) provides a service to seek the three "common" European mutations.

Liver biopsy

The minimum amount is $3-5 \mathrm{mg}$ dry weight, about $1 \mathrm{~cm}$ biopsy length. This must not be put into fixative. Contact the receiving trace metal laboratory before obtaining the biopsy sample.

Isotope incorporation

Sequential $2 \mathrm{ml}$ serum samples are required. Request details from the specialist laboratory. Copper isotope protocols can be obtained from Trace Metals Unit, Department of Biochemistry, Royal Infirmary, Castle Street, Glasgow G4 OSF, UK (tel: +440141 211 4638).

\section{Summary points}

- Wilson's disease is the most common inherited disorder of copper metabolism. It is characterised by low serum copper and caeruloplasmin concentrations coupled with the pathological accumulation of copper in the tissues.

- The clinical presentation is very variable. In young patients hepatic disorders dominate with neurological manifestations becoming increasingly important in older subjects.

- A low serum copper and caeruloplasmin concentration coupled with an increased urinary copper excretion, which may be further augmented in response to penicillamine, will enable a diagnosis to be made in most cases. However, patients presenting with acute hepatic necrosis may have an increased serum copper concentration coupled to an increased non-caeruloplasmin bound copper.
- There are no characteristic histological features of Wilson's disease. However, measuring liver copper concentration is a cornerstone of diagnosing the condition.

- Stable copper isotope $\left({ }^{65} \mathrm{Cu}\right)$ studies, because of their safety and ease, have replaced radioisotope studies in making the diagnosis and investigating copper metabolism.

- Because of the genetic heterogeneity of the condition, DNA studies are unhelpful diagnostically but may be useful in family studies.

- Patients are best treated by specialist centres with experience and expertise in the condition.

Thanks to Dr David Lyon and Dr David Halls (trace metals unit, department of biochemistry, Glasgow Royal Infirmary); Professor Diane Wilson Cox (Edmonton, Alberta) for advice and help; Dr Diana Curtis (Sheffield) for discussions; Barbara McGill Trust (Altewan Farm, Maybole, Ayrshire) for funding of McGill Trus
research.

1 Weatherall DJ, Ledingham JGG, Warrell DA, eds. Oxford textbook of medicine, 3rd ed, Vol. 2. Oxford: Oxford University Press, 1996.

2 Scheinberg IH, Sternlieb I. Wilson's disease. Philadelphia: Saunders, 1984

3 Davis W, Chowrimootoo GFE, Seymour CA. Defective biliary copper excretion in Wilson's disease: the role of caeruloplasmin. Eur f Clin Invest 1996;26:893-901.

4 Dameron C and colleagues and Howe PD. Wilson disease. In: Environmental health criteria 200: copper. Geneva: World In: Environmental health criteria 200:c

5 Sternlieb I, Scheinberg IH. Wilson's disease. In: Wright R, Millward-Soler GH, Alberti KGMM, et al, eds. Liver and biliary disease. London: WB Saunders, 1985:949-61.

6 O'Donnell JG, Watson ID, Fell GS, et al. Wilson's disease presenting as acute fulminant hepatic failure. Scott Med $\mathcal{F}$ 1990;35:118-19.

7 Kalach N, Seidman EG, Morin C, et al. Acute liver failure from Wilson's disease in a five-year-old child. Can f Gastroenterol 1993;7:610-12.

8 Gollan JL, Gollan TJ. Wilson disease in 1998: genetic, diagnostic and therapeutic aspects. F Hepatol 1998;28:28-36.

9 Steindl P, Ferenci P, Dienes HP, et al. Wilson's disease in patients presenting with liver disease: a diagnostic chalpatients presenting with liver disease: a

10 Brewer GJ. Practical recommendations and new therapies for Wilson's disease. Drugs 1995;50:240-9.

11 Walshe JM. The discovery of the therapeutic use of D-penicillamine. F Rheumatol 1981;7:3-8.

2 Walshe JM. The management of pregnancy in Wilson's disease treated with trientine. $Q 7 M$ 1986:58:81-7.

13 Chou MS, Kuo Y-T, Wang C-K, et al. MRI manifestations in Wilson's disease and its change in response to treatment. Rivista di Neuroradiologia 1998;11(suppl 2):31-4.

14 Huang C-C, Chu N-S. Wilsons's disease: resolution of MRI lesions following long term oral zinc therapy. Acta Neurol Scand 1996;93:215-18

15 Walshe JM, Dixon AK. Dangers of non-compliance in Wilson's disease. Lancet 1986;1:845-7.

16 Frydman M, Bonne-Tamir B, Farrer LA, et al. Assignment of the gene for Wilson disease to chromosome 13. Linkage to esterase D locus. Proc Natl Acad Sci U S A 1985;82:1819-21.

17 Bull PC, Thomas GR, Rommens JM, et al. The Wilson disease gene is a putative copper transporting P-type ATPase similar to the Menkes gene. Nat Genet 1993;5:327-37.

18 Tanzi RE, Petrushin K, Chercov I, et al. The Wilson disease gene is a copper transporting ATPase with homology to the Menkes disease gene. Nat Genet 1993;5:344-50.

19 Yamaguchi Y, Heiny ME, Shimizu N, et al. Expression of the Wilson disease gene is deficient in the Long-Evans Cinnamon rat. Biochem 7 1 1994;301:1-4.

20 Tsai C-S, Tsai F-J, Wu J-Y, et al. Mutation analysis of Wilson disease in Taiwan and description of six new mutations. son disease in Taiwan and desc

21 Roberts EA, Cox DW. Wilson disease. Baillieres Clin Gastroenterol 1998;12:237-56.

22 Loudianos G, Dessi V, Lovicu M, et al. Further delineation of the molecular pathology of Wilson disease in the Mediterranean population. Hum Mutat 1998;12:89-94.

23 Thomas GR, Forbes JR, Roberts EA, et al. The Wilson disease gene: spectrum of mutations and their consequences. Nat Genet 1995;9:210-17.

24 Maier-Dobersberger T, Mannhalter C, Rack S, et al. Diagnosis of Wilson's disease in an asymptomatic sibling by DNA linkage analysis. Gastroenterology 1995;109:201518 .

25 Danks DM. Disorders of copper transport. In: Scriver CR, Beaudet AL, Sly WS, et al, eds. The metabolic and molecular
basis of inherited disease, 7 th ed, Vol. II. New York: McGraw basis of inherited disease,
Hill, 1995:2211-35. 
26 Tu JB, Blackwell RQ. Studies on levels of penicillamineinduced cupriuresis in heterozygote of Wilson's disease. Metabolism 1967;16:507-13.

27 AW Walker, ed. SAS trace elements analysis. Royal Surrey County Hospital, Guildford, UK, 1998.

28 Da Costa CM, Baldwin D, Portmann B, et al. Value of urinary copper excretion after penicillamine challenge in the diagnosis of Wilson's disease. Hepatology 1992;15:60915.

29 Faa G, Nurchi V, Demilia L, et al. Uneven hepatic copper distribution in Wilson's disease. F Hepatol 1995;22:303-
30 Lyon TDB, Fell GS, Gaffney D, et al. Use of a stable copper isotope $\left({ }^{65} \mathrm{Cu}\right)$ in the differential diagnosis of Wilson's disease. Clin Sci 1995;88:727-32.

31 Gaffney D, Walker JL, O'Donnell JG, et al. DNA-based presymptomatic diagnosis of Wilson's disease. F Inherit Metab Dis 1992;15:161-70.

32 Thomas GR, Bull PC, Roberts EA, et al. Haplotype studies in Wilson disease. Am f Hum Genet 1994;54:71-8.

33 Loudianos G, Figus AL, Loi A, et al. Improvement of prenatal diagnosis of Wilson disease using microsatellite markers. Prenat Diagn 1994;14:999-1002.

\section{PATHOLOGY INTERACTIVE 2000}

Do you know ... ?

Pathology Interactive Volume 2 now offers:

Up to three CPD credits per review article

1 credit for reading the article and completing the associated questions

1 credit for additional reading, following up references

1 credit for making notes, identifying learning outcome or identifying further learning needs

CPD credits for working on articles outside your specialty

Pathology Interactive Volume 2 Issue 1 includes articles in:

Microbiology

Histopathology

Molecular pathology

Further issues in $\mathbf{2 0 0 0}$ will cover further articles in these specialties, plus:

Chemical pathology

Haematology

Immunology

Including case study and picture quiz formats

Pathology Interactive 2000 Volume 2, 4 issues (March, June, September, December) ISSN 1466 5743. Accredited by the Royal College of Pathologists

Subscription rate: $£ 75+$ VAT personal ${ }^{\star}, £ 150+$ VAT institutional (multiuser rate on application to the publisher).

Send orders to: BMJ Publishing Group, Journals Marketing Dept, PO Box 299, London WC1H 9TD, UK; fax credit card orders to: +44 (0)20 7383 6402; call subscriptions hotline +44(0)20 7383 6270; email orders to: subscriptions@bmjgroup.com

*ACP members receive Pathology Interactive with their copy of fournal of Clinical Pathology, as a membership benefit. 